\title{
Lysophosphatidylcholine increases rat ileal permeability to macromolecules
}

\author{
C TAGESSON, L FRANZÉN, G DAHL, AND B WESTRÖM \\ From the Departments of Clinical Chemistry, Occupational Medicine, and Pathology II, Linköping \\ University, and Department of Zoophysiology, University of Lund, Sweden
}

SUMMARY The influence of lysophosphatidylcholine (LPC) on macromolecular permeability in the distal ileum has been studied. Using a rat experimental model, we determined the intestinal permeability to different sized dextrans (3000-70 000 daltons) and bovine serum albumin (BSA) in the absence and presence of LPC. We also examined the morphology of the ileal mucosa after deposition of LPC in the gut lumen, and determined N-acetyl- $\beta$-glucosaminidase, $5^{\prime}$ nucleotidase, and alkaline phosphatase activities in suspensions of isolated mucosal cells and different concentrations of LPC. We found that $20 \mathrm{mM} \mathrm{LPC} \mathrm{damaged} \mathrm{the} \mathrm{ileal} \mathrm{mucosa} \mathrm{and} \mathrm{that} \mathrm{it}$ increased its permeability to all the molecules investigated. Moreover, mixtures of mucosal cells and $0 \cdot 01-1 \mathrm{mM}$ LPC showed increased $\mathrm{N}$-acetyl- $\beta$-glucosaminidase activity: the higher the LPC concentration, the higher the enzyme activity. These findings indicate that LPC, a naturally occurring surfactant in the intestine, might damage mucosal cells and release lysosomal enzyme activity, and that higher LPC concentrations may impair the mucosal barrier function and increase the gut permeability to macromolecules such as proteins. This could have relevance to the development of various disease states, in which increased intestinal absorption of macromolecules is of importance.

Intestinal absorption of macromolecules may be of critical importance to the pathogenesis of many diseases, especially those involving allergic reactions to ingested foreign substances or toxic reactions to bacterial and parasitic products. ${ }^{1}$ Little is known, however, about the mechanisms by which the absorption of macromolecules could be facilitated in various disease states. Chadwick et $a l^{2}$ recently showed that some of the naturally occurring bile acids in man can alter rabbit colonic structure and function, and that bile acid induced fluid secretion was invariable associated with epitheliolysis and increased mucosal permeability. Alternatively, we have found that another naturally occurring detergent, lysophosphatidylcholine (LPC), can impair the mucosal barrier in the distal part of rat ileum and thus enable larger molecules such as dextran 3000 to traverse the intestinal wall. ${ }^{3}$ The detailed mechanisms behind this effect are not known, however, and it is therefore unclear whether LPC may increase also the permeability to larger

Address for correspondence: Christer Tagesson, MD, Department of Occupational Medicine, Linköping University, S-581 85 Linköping, Sweden. Received for publication 1 June 1984 macromolecules such as proteins.

The present study was conducted with a view to obtain more detailed information concerning how LPC might influence intestinal permeability to larger molecules. We therefore investigated the influence of LPC on rat intestinal permeability to larger dextrans (3000-70 000 daltons) and to bovine serum albumin, a 70000 dalton protein. In addition, we examined the morphology of the ileal mucosa after deposition of LPC in the bowel lumen, and determined $\mathrm{N}$-acetyl- $\alpha$-glucosaminidase, 5 '-nucleotidase, and alkaline phosphatase activities in mixtures of isolated mucosal cells and LPC. The results indicate that LPC may act as a detergent and release lysosomal enzymes from mucosal cells in vitro, and that higher LPC concentrations increase the shedding of enterocytes at the villous tips and augment the mucosal permeability to dextran 70000 and bovine serum albumin.

\section{Methods}

CHEMICALS

Fluorescein-isothiocyanate (FITC) conjugated 
dextrans with molecular weights of 3000 and 10000 daltons were purchased from Pharmacia Fine Chemicals, Uppsala, Sweden, whereas FITCdextran 70000 was bought from Sigma Chemical Company, St Louis, Missouri, USA. Lysophosphatidylcholine (1-acyl-sn-glycero-3phosphocholine) was Sigma type I, whereas bovine serum albumin was Sigma type V.

\section{PERMEABILITY MEASUREMENTS}

All experiments were carried out on 225-250 g female Sprague-Dawley rats maintained on a standard laboratory diet. They were anaesthetised by an intraperitoneal injection of Ketalar ${ }^{\circledR}$ (Parke, Davis, Pontypool, UK; $50 \mathrm{mg} / \mathrm{kg}$ body weight) and Rompun ${ }^{\circledR}$ (Bayer AG, Leverkusen, West Germany; $5 \mathrm{mg} / \mathrm{kg}$ body weight $)$. A polyethylene catheter $(\theta=$ $0.96 \mathrm{~mm}$ ) was placed in one of the carotid arteries. Thereafter, a $10 \mathrm{~cm}$ segment of the distal ileum immediately proximal to the caecum was converted to a tied loop. Before ligating the proximal end, a flexible cannula with an injection valve was put into the segment through a separate insertion. The permeability markers (FITC-dextran 3000, 10000 , or a mixture of FITC-dextran 70000 and bovine serum albumin) were dissolved in $1 \mathrm{ml} 150 \mathrm{mM}$ $\mathrm{NaCl}$ together with (or without) $20 \mathrm{mM} \mathrm{LPC}$ or $1 \%$ Triton X-100, and instilled into the loop. Blood samples $(200 \mu \mathrm{l})$ were withdrawn from the carotid artery before instillation and at intervals thereafter. The samples were analysed for FITC-dextrans and/ or bovine serum albumin.

To determine the concentration of FITC-dextran, the sample was mixed with $3.8 \mathrm{ml}$ Tris $(50 \mathrm{mM})$ $\mathrm{NaCl}(150 \mathrm{mM}), \mathrm{pH} 10 \cdot 3$, and centrifuged at $2800 \mathrm{~g}$ for five minutes. The supernatant was then analysed for FITC-dextran by using fluorescence spectrometry as described elsewhere. ${ }^{3}$ Bovine serum albumin in serum was determined by electroimmunoassay using crystallised bovine serum albumin (Sigma type A 7638) as standard. ${ }^{4}$ Specific antiserum to bovine serum albumin was obtained from Miles Laboratories (Freehold, USA).

\section{MORPHOLOGY}

Tied loops prepared as above were either left unfilled or filled with $1 \mathrm{ml} 150 \mathrm{mM}$ phosphate buffered saline (PBS), $20 \mathrm{mM}$ LPC in $1 \mathrm{ml}$ PBS, or $1 \%$ Triton X-100 in $1 \mathrm{ml}$ PBS. After 30 minutes, 300 $\mathrm{ml} 2 \%$ glutaraldehyde in $0.1 \mathrm{M} \mathrm{Na}$-cacodylate- $\mathrm{HCl}$ with $0.1 \mathrm{M}$ sucrose and $2 \%$ polyvinylpyrrolidone (PVP, molecular weight 44000 daltons) was perfused via the heart. ${ }^{56}$ The perfusion was conducted during 10 minutes at a constant hydrostatic pressure of $110 \mathrm{mmHg}$. The $\mathrm{pH}$ of the fixative was $7 \cdot 2$, its temperature $37^{\circ} \mathrm{C}$ and its total osmolality about $560 \mathrm{mOsm}$ (vehicle osmolality about $300 \mathrm{mOsm}$ ).

For light microscopy, five $2 \mathrm{~mm}$ thick segments were sampled from each loop and immersed in the above fixative for another three days at $4^{\circ} \mathrm{C}$. The specimens were then dehydrated, embedded in Sorwall JB4 resin, cut into $3 \mu \mathrm{m}$ thick sections and stained with either haematoxylin eosin, haematoxylin van Gieson, or $0.5 \%$ toluidine blue at $\mathrm{pH} 4$.

The morphological changes in villous tips were quantitatively assessed by examining intestinal circumferences in sections stained with haematoxylin van Gieson. Tips were thus classified into three categories according to their morphological appearance: (i) normal morphology with regular columnar epithelium, (ii) moderately changed morphology with loss of columnar characteristics, partial desquamation, karyolysis and karyorrhexis, and (iii) severely changed morphology with patchy desquamation of epithelium leaving denuded areas of basal membrane. A mean of 36 villi (range 22-69) were examined in each circumferential section.

For transmission electron microscopy, two $1 \mathrm{~mm}$ wide segments of each loop were immersed in the above fixative for another three days at $4^{\circ} \mathrm{C}$. Three 1 $\mathrm{mm}$ cubic pieces were taken from each segment, rinsed in $0.15 \mathrm{M} \mathrm{Na}$-cacodylate- $\mathrm{HCl}$ buffer (CAC) and postfixed in $1 \% \mathrm{OsO}_{4}$ in $0.15 \mathrm{M}$ CAC. After another rinse in $0.15 \mathrm{M} \mathrm{CAC}$, the specimens were 'stained' in 2\% uranyl acetate in 50\% ethanol over night. After dehydration in a graded ethanol series and embedding in Epon 812, the specimens were cut with diamond knives on a LKB III ultratome, stained with lead citrate and examined in a Philips 300 electron microscope at $60 \mathrm{kV}$.

INFLUENCE ON MUCOSAL CELLS IN VITRO

The distal ileum (about $20 \mathrm{~cm}$ ) was excised and the faecal contents removed. The mucosa was then scraped off with a curette. Special precaution was taken to scrape only the superficial layers of the mucosa. The cells were suspended in Krebs-Ringer phosphate buffer containing $10 \mathrm{mM}$ glucose (KRG) and $0.5 \%(\mathrm{w} / \mathrm{v})$ trypsin to a concentration of $15 \mathrm{mg}$ tissue/ml. This suspension was subjected to magnetic stirring for 30 minutes, Vortex-mixed for 1 minute, and filtered through gauze. The filtrate was centrifuged $(800 \mathrm{~g}, 10 \mathrm{~min})$, the supernatant discarded, and the pellet resuspended in KRG. One hundred microlitres of this cell suspension was then mixed with $100 \mu \mathrm{l}$ LPC (final concentration 0.01-1 $\mathrm{mM}$ ), and the mixture incubated at room temperature for 30 minutes. The activities of alkaline phosphatase, ${ }^{7} 5^{\prime}$-nucleotidase ${ }^{89}$ and $\mathrm{N}$ - 
acetyl- $\beta$-glucosaminidase ${ }^{810}$ were then determined. To study the influence of LPC on non-lysosomal $\mathrm{N}$-acetyl- $\beta$-glycosaminidase, the mucosal cells were disintegrated in a glass homogenizer, subjected to three freeze-thawing cycles, and centrifuged at $30000 \mathrm{~g}$ for 30 minutes. The supernatant was then withdrawn and used for further experimentation. The material was incubated with varying concentration (0.001-10 mM) LPC as described above, and the activity of $\mathrm{N}$-acetyl- $\beta$-glucosaminidase determined.

\section{STATISTICAL DETERMINATIONS}

Statistical analysis were carried out with the use of Student's $t$ test.

\section{Results}

INFLUENCE OF LPC ON INTESTINAL PERMEABILITY The intestinal absorption into blood of different sized dextrans in the absence and presence of LPC is illustrated in Figure 1. After deposition in the absence of LPC, only minute amounts of dextran 3000 were found in the circulation, whereas in the presence of LPC considerable amounts were found. Lysophosphatidylcholine also enhanced the transfer of dextran 10000 , although as shown in Figure 1, the transfer of dextran 10000 was less than that of dextran 3000. For comparison, the influence of Triton X-100, a non-ionic detergent, on the permeability to dextran 3000 and 10000 is also shown in Figure 1. Thus, like LPC, Triton X-100 significantly augmented the permeability both to dextran 3000 and 10000 (Fig. 1, right).

The influence of LPC on the transfer of dextran 70000 and bovine serum albumin is illustrated in Figure 2. We thus found that the presence of LPC significantly increased the absorption also of these two compounds.

\section{INFLUENCE ON INTESTINAL MORPHOLOGY}

The operative procedure by itself had no apparent influence on the morphology of the intestine. Instillation of PBS (with or without LPC or Triton $\mathrm{X}-100$ ) caused a slight distention of the loop and a flattening of the mucosa with broadening of the villi. No apparent infiltration of inflammatory cells was found in the mucosa after either treatment. Phosphate buffered saline alone had no evident effect on epithelial morphology as seen by light microscopy (Fig. 3) or by transmission electron microscopy. On the other hand, instillation of LPC or Triton X-100 caused profound changes of the epithelium along most of the villous tips (Fig. 3). These changes included loss of columnar characteristics and varying degrees of karyorrhexis and

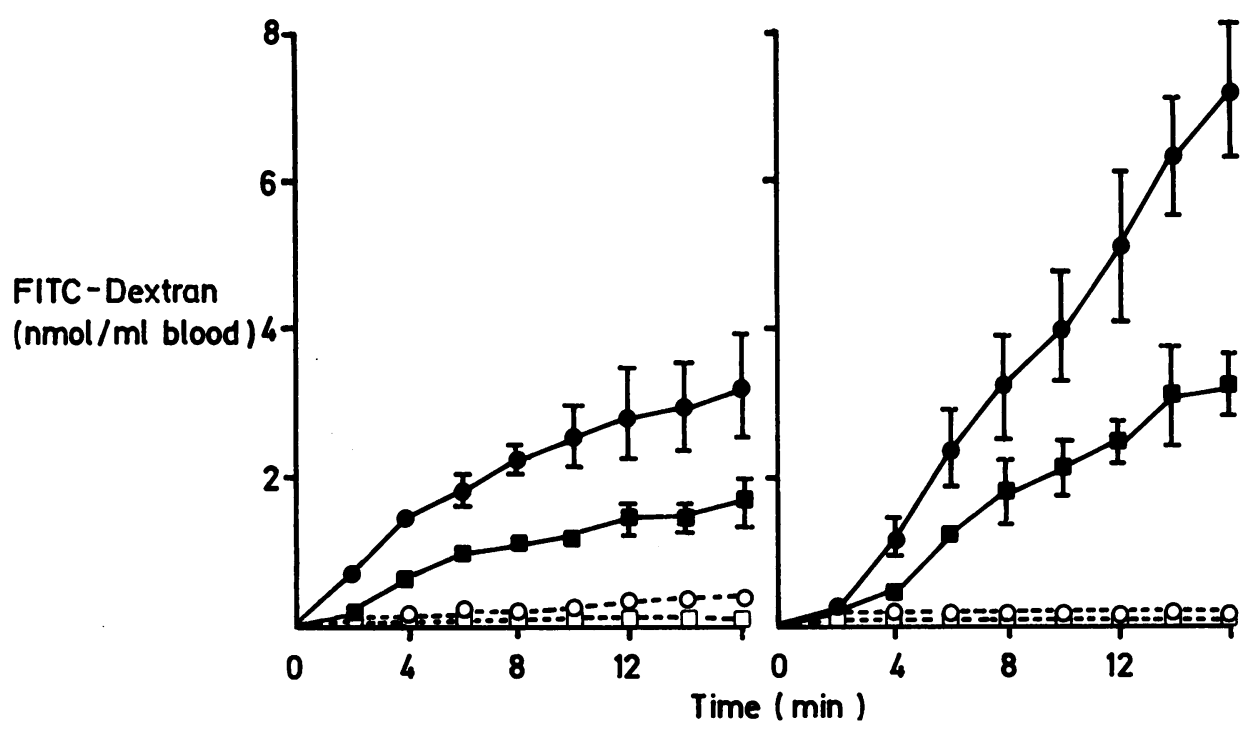

Fig. 1 Influence of $20 \mathrm{mM} \mathrm{LPC} \mathrm{(left)} \mathrm{and} \mathrm{1 \%} \mathrm{Triton} \mathrm{X-100} \mathrm{(right)} \mathrm{on} \mathrm{intestinal} \mathrm{permeability} \mathrm{to} \mathrm{FITC-dextran} 3000$ (O) and 10000 (口). Permeability in the absence of LPC and Triton X-100, respectively, is indicated by open symbols ((O) FITC-dextran 3000, (口) FITC-dextran 10 000). The ordinate shows the blood concentration at different times after deposition of $3.3 \mathrm{mM}$ FITC-dextran in the distal ileum. Mean of five experiments, vertical bars indicate standard error of the mean. 


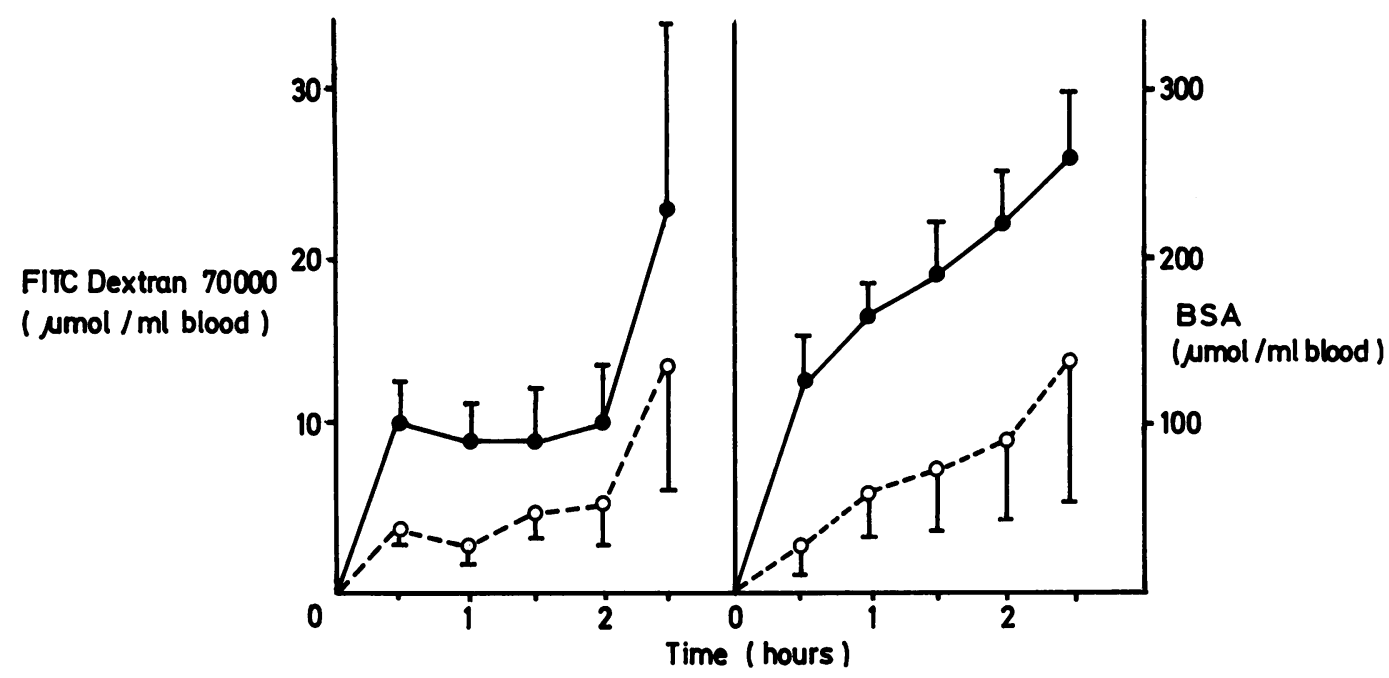

Fig. 2 Intestinal permeability to FITC-dextran 70000 (left) and bovine serum albumin (right) in the absence $(O)$ and presence $(\mathbf{O})$ of $20 \mathrm{mM} L P C$. The ordinate shows the serum concentration at different times after deposition of a mixture of FITC-dextran $70000(50 \mathrm{mg} / \mathrm{ml})$ and bovine serum albumin $(50 \mathrm{mg} / \mathrm{ml})$ in the distal ileum. Mean of 6-10 experiments; vertical bars indicate standard error of the mean.

karyolysis. Furthermore, both partial desquamation with cells still sticking to the remaining covering epithelium and total desquamation were seen. When the degree of morphological changes in the villous tips was quantitatively assessed, the epithelial damage after instillation of Triton X-100 was found to be more pronounced than that after instillation of LPC (Table).

Ultrastructurally, the above findings were verified. A reduction in number of microvilli,

Table Quantitative assessment of the influence of $L P C$ and Triton X-100 on intestinal morphology. The Table shows the percentage of villous tips showing different degrees of morphological changes after exposure to the various agents. Moderate changes include loss of columnar characteristics, karyorrhexis, karyolysis or partial desquamation, whereas severe changes represent total desquamation of epithelium leaving some areas of the basal membrane denuded. A mean of 36 villi (range 22-69) were examined in each intestinal circumference. Values are mean $\pm S E M$

\begin{tabular}{lllll}
\hline & $\begin{array}{l}\text { Circum- } \\
\text { ferences } \\
\text { counted (no) }\end{array}$ & \multicolumn{4}{l}{ Morphological changes } \\
\cline { 3 - 5 } Agent & 10 & None & Moderate & Severe \\
\hline None & 10 & $95 \cdot 0 \pm 1 \cdot 5$ & $5 \cdot 0 \pm 1 \cdot 5$ & \\
PBS & 10 & $11 \cdot 7 \pm 4 \cdot 4$ & $9 \cdot 0 \pm 4 \cdot 4$ & \\
LPC $(20 \mathrm{mM})$ & $10 \cdot 9 \pm 2 \cdot 8$ & $7 \cdot 5 \pm 3 \cdot 5$ \\
Triton X-100 $(1 \%)$ & 9 & $1 \cdot 2 \pm 0 \cdot 9^{*}$ & $59 \cdot 6 \pm 7 \cdot 4^{*}$ & $39 \cdot 2 \pm 7 \cdot 7 \dagger$ \\
\hline
\end{tabular}

* $\mathrm{p}<0.01$ vs LPC treatment. $\dagger \mathrm{p}<0.001$ vs LPC treatment. swelling of mitochondria and cytoplasmic vesiculation were noted after treatment with either LPC (Fig. 4a) or Triton X-100. Furthermore, Triton $\mathrm{X}-100$ caused more pronounced damage with total epithelial desquamation of many villous tips (Fig. $4 b$ ). Tight junctions were sometimes opened up between clearly degenerating cells still sticking to the basal membrane, but not between normal or only slightly damaged cells.

INFLUENCE ON MUCOSAL CELLS IN VITRO

The influence of LPC on activities of alkaline phosphatase, 5'-nucleotidase, and $\mathrm{N}$-acetyl- $\beta$ glucosaminidase from isolated mucosal cells in vitro is illustrated in Figure 5. Thus, mixtures of mucosal cells and increasing LPC concentrations showed increased enzyme activity: the higher the LPC concentration, the higher the enzyme activity. In the presence of $1 \mathrm{mM}$ LPC, the $\mathrm{N}$-acetyl- $\beta$ glucosaminidase was increased 4.8 times over that attained in the absence of LPC, whereas corresponding values for alkaline phosphatase and 5 -nucleotidase were 1.7 and 1.5 , respectively. By contrast, there was no significant influence of 1 $\mu \mathrm{M}-10 \mathrm{mM}$ LPC on the $\mathrm{N}$-acetyl- $\beta$-glucosaminidase in a $30000 \mathrm{~g}$ supernatant fraction of disintegrated mucosal cells.

Discussion

Altered intestinal permeability to food constituents 

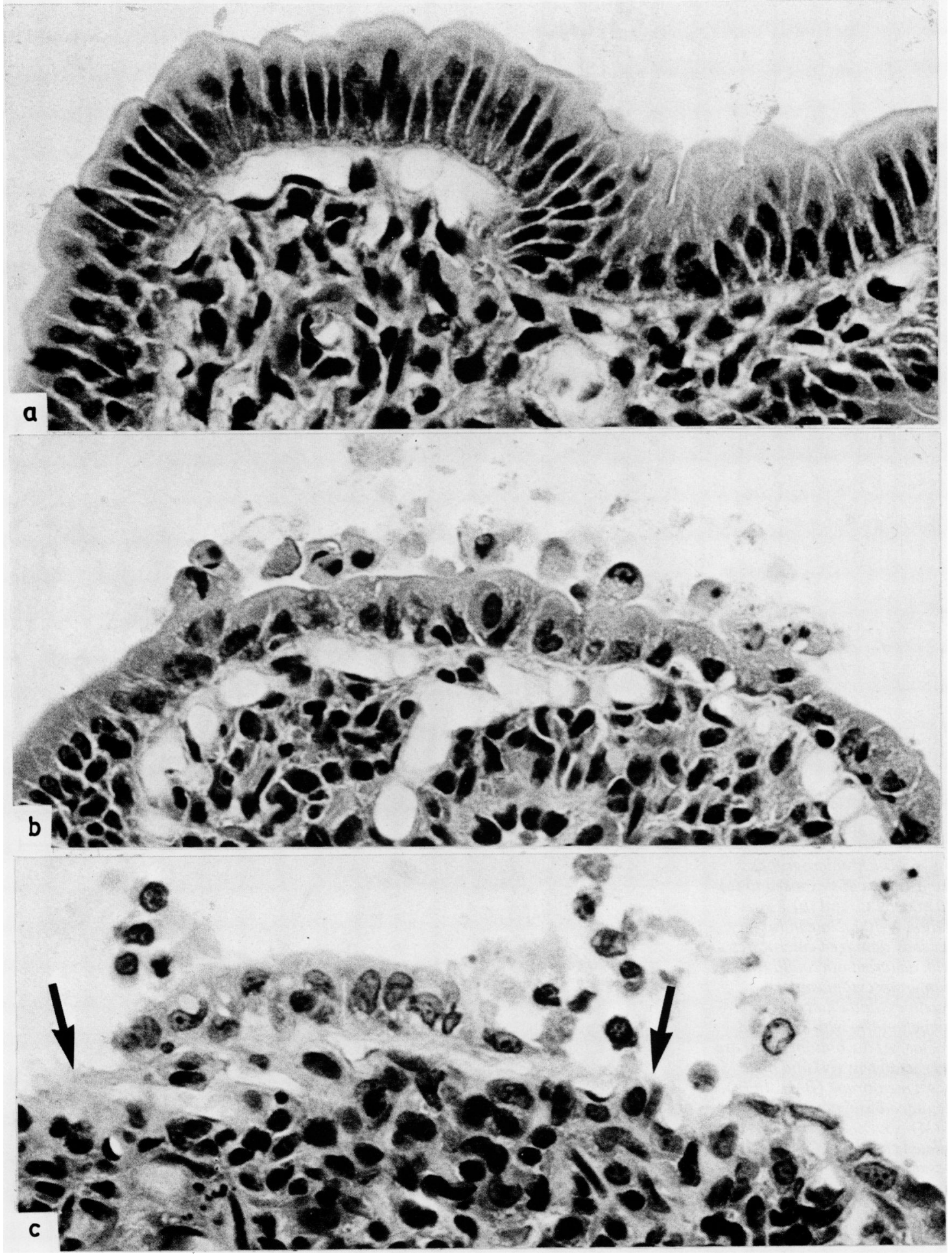

Fig. 3 Photomicrographs of intestinal villi exposed to (a) PBS, (b) $20 \mathrm{mM} \mathrm{LPC}$, and (c) $1 \%$ Triton $X-100$. (Weigert's haematoxylin-eosin; 570$)$. In (a) the villus is covered with regular columnar epithelium whereas in $(b)$ the epithelium is degenerated and partially desquamated - that is, some cells are still sticking to the remaining epithelium. A total desquamation of epithelium with denuded basal membrane is seen in (c) (arrows). (The dilated capillaries under the basal membrane of villous tips in $(a)$ and $(b)$ are due to the perfusion fixation). 
Fig. 4 TEM micrographs

from villous tips exposed to (a) $20 \mathrm{mM} \mathrm{LPC}$, and (b) $1 \%$

Triton $X-100$. Note in (a) severely damaged enterocytes with distorted microvilli $(M)$, numerous cytoplasmic vacuoles, and dilated mitochondria with disrupted cristae. At the bottom of (a) are seen a nucleus $(N)$ and the basal membrane (BM). In (b), denuded basal membrane $(B M)$ is seen. Note also in (b) dilated capillary $(C)$ beneath basal membrane (effect of perfusion fixation).






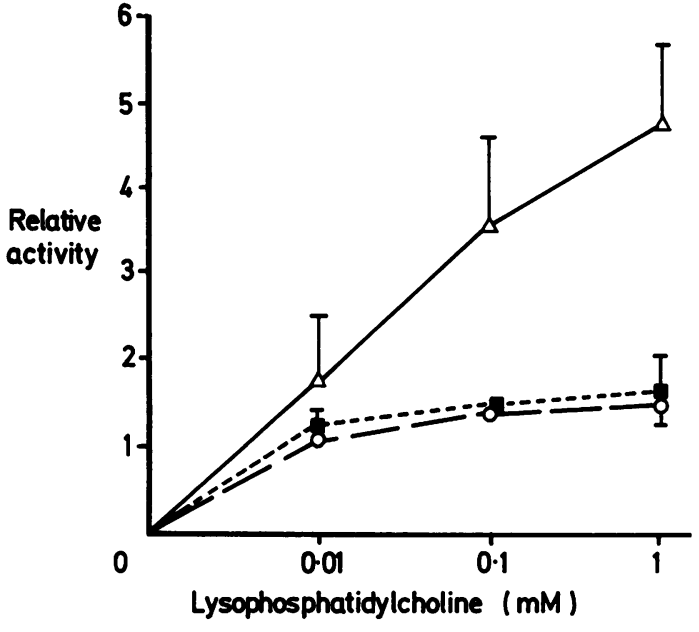

Fig. 5 Activities of alkaline phosphatase ( $\square$ ),

5 'nucleotidase (O), and $N$-acetyl- $\beta$-glucosaminidase $(\mathbf{\Delta})$ in mixtures of rat intestinal mucosal cells and different $L P C$ concentrations. The ordinate shows enzyme activity relative to the activity in the absence of LPC. Mean of three experiments; vertical bars indicate standard error of the mean.

and microbial products may underlie the pathogenesis of a variety of diseases. Accordingly, increased absorption of macromolecules has been claimed to occur in coeliac disease, chronic inflammatory bowel disease, IgA deficiency, food allergy, various liver diseases, and others. ${ }^{11-15}$ Little is known, however, about the mechanisms by which intestinal uptake of macromolecules might be facilitated in these disease states. Although certain bile acids, ${ }^{2} 1617$ synthetic detergents, ${ }^{18}$ and traumatic injury ${ }^{19}$ all have been shown to increase gut permeability to macromolecules in various experimental systems, their role in the development of gastrointestinal disease has not been established. Analogously, we recently found that LPC increased the permeability to dextran $3000,{ }^{3}$ but the biological significance of this finding is as yet unclear.

The present study shows that LPC may increase the intestinal permeability not only to dextran 3000 , but also to dextran 10000 and, indeed, 70000 . It also shows that LPC may augment the intestinal absorption into blood of bovine serum albumin, a 70000 dalton protein (Fig. 2). Moreover, LPC apparently released considerable amounts of lysosomal enzyme from mucosal cells in vitro (Fig. 5 ), and increased the shedding of enterocytes from villous tips in vivo (Fig. 3). These findings indicate that LPC might damage mucosal cells and impair the intestinal barrier function in the distal part of the ileum. As a consequence, the intestinal mucosa may allow permeation of potentially antigenic, toxic or carcinogenic material.

The mechanism by which LPC may damage the intestinal mucosa has not been elucidated. We found, however, that much the same or even greater influence than LPC on mucosal structure and permeability was obtained with Triton X-100, a non-ionic detergent. It can be hypothesised, therefore, that the observed effects of LPC can be attributed to its detergent properties. Detergents can alter gut permeability ${ }^{20}$ and damage cell membranes ${ }^{21}$ although the exact mechanism by which they interact with membranes is only incompletely understood. If LPC-protein interactions are disregarded, increasing LPC concentrations in the phospholipid bilayer will lead to either a generally enhanced membrane permeability by increased membrane 'fluidity', or to the formation of actual pores. ${ }^{22}$ Also partial micellisation and solubilisation of membrane lipids have to be considered. Both reactions will finally lead to free ion permeation and subsequent osomotic rupture of the cell. Analogously, if the binding affinity of LPC to some integral membrane proteins are high, the accumulation of lysolipid around proteins might result in an extraction of proteins into micelles and, again, formation of 'pores' in the membranes. ${ }^{22}$ This could explain why LPC 'released' $\mathrm{N}$-acetyl- $\beta$ glucosaminidase, a membrane-bounded lysosomal enzyme from the mucosal cells, but had little influence on brush border enzymes such as alkaline phosphatase and 5'-nucleotidase (Fig. 5).

We have thus obtained some evidence to indicate that LPC, a naturally occurring detergent, may impair the mucosal barrier in the rat ileum and so facilitate the intestinal transmission of macromolecules. The relevance of this finding to the development of human disease states remains to be established. Ammon et $a l^{23}$ recently showed that LPC affects rat intestinal transport in the same way as bile acids, fatty acids and synthetic cationic or nonionic detergents, and argued, by comparison with the response of the human jejunum to taurodeoxycholate, that it is likely that LPC generated during the normal process of digestion has a significant influence on intestinal transport in the postprandial phase under physiological conditions. The postprandial concentrations of LPC in the human jejunum range from $2 \mathrm{mM}$ to $4 \mathrm{mM}^{2425}$ whereas little is known about LPC concentrations in the distal part of the small intestine. It cannot be ruled out, however, that higher concentrations of LPC might occur, particularly if the mucosa is less capable than normal to remove LPC. We recently found that the activity of lysophospholipase was 
decreased in ileal mucosa of patients with Crohn's disease and suggested that the mucosa could be less well equipped to handle LPC and, therefore, predisposed for mucosal injury induced by LPC. ${ }^{26}$ This possibility should not be entirely overlooked because LPC is generated in inflammatory foci, ${ }^{27}$ has a range of cytotoxic and non-cytotoxic effects on diverse cells ${ }^{28-32}$ and, as shown in this investigation, may enhance the mucosal permeability to potentially antigenic and toxic molecules.

We acknowledge gratefully the excellent technical assistance of Berit Johansson and Rita Grandér. This work is supported by grants from the National Swedish Association against Rheumatism, the Swedish Natural Science Research Council, and the Swedish Medical Research Council (B 83-17X05983-03B).

\section{References}

1 Walker WA. Antigen absorption from the small intestine and gastrointestinal disease. Pediatr Clin $N$ Am 1975; 22: 731-8.

2 Chadwick VS, Gaginella TS, Carlsson GL, De Gonguie JC, Phillips SF, Hofmann A. Effect of molecular structure on bile acid-induced alterations in absorptive function, permeability, and morphology in perfused rabbit colon. J Lab Clin Med 1979; 94: 661-74.

3 Bolin T, Sjödahl R, Sundquist T, Tagesson C. Passage of molecules through the wall of the gastrointestinal tract. Increased passive permeability in rat ileum after exposure to lysolecithin. Scand J Gastroenterol 1981; 16: 897-901.

4 Laurell C-B. Quantitative estimation of proteins by electrophoresis in agarose gel containing antibodies. Anal Biochem 1966; 15: 45-52.

5 Bohman SO, Maunsbach AB. Effects of tissue fine structure of variations in colloid osmotic pressure of glutaraldehyde fixatives. $J$ Ultrastr Res 1970; 30: 195-208.

6 Collins VP, Arborgh, B, Brunk U. A comparison of the effects of three widely used glutaraldehyde fixatives on cellular volume and structure. Acta Path Microbiol Scand Sect A 1977; 85: 157-68.

7 Peters TJ, Heath JR, Wansbrough-Jones $\mathrm{MH}$, Doe WF. Enzyme activities and properties of lysosomes and brush borders in jejunal biopsies from control subjects and patients with coeliac disease. Clin Sci Mol Med 1975; 48: 259-67.

8 Peters TJ. Analytical subcellular fractionation of jejunal biopsy specimens: Methodology and characterization of the organelles in normal tissue. Clin Sci Mol Med 1976; 51: 557-74.

9 Douglas AP, Kerley R, Isselbacher KJ. Preparation and characterization of the lateral and basal plasma membrane of the rat intestinal epithelial cell. Biochem $J$ 1972; 128: 1329-38.

10 Tagesson C, Bolin T, Heuman R, Magnusson K-E, Norrby K, Sjödahl R. Subcellular fractionation of human intestinal mucosa by large-scale zonal fractionation. Characterization of subcellular organelles in the distal part of the ileum. Scand J Gastroenterol 1980; 15: 353-62.

11 Kievel RM, Kearns DH, Liebowitz D. Significance of antibodies to dietary proteins in serum of patients with nontropical sprue. $N$ Engl J Med 1964; 271: 769-72.

12 Menzies JS, Pounder R, Heyer S et al. Abnormal intestinal permeability to sugars in villous atrophy. Lancet 1979; 2: 1107-9.

13 Ward M. The pathogenesis of Crohn's disease. Lancet 1977; 1: 903-5.

14 Wands JR, Lamont JT, Mann E, Isselbacher $\mathrm{K}$. Arthritis associated with intestinal by-pass procedure for morbid obesity. Complement activation and character of circulating cyroproteins. $N$ Engl J Med 1976; 294: 121-9.

15 Walker WA. Intestinal transport of macromolecules. In: Johnson LR, ed. Physiology of the gastrointestinal tract. New York: Raven Press, 1981: 1271-89.

16 Fagundes-Neto V, Teichberg S, Bayne MA, Morton B, Lifshitz F. Bile salt-enhanced rat jejunal absorption of macromolecular tracer. Lab Invest 1981; 44: 18-26.

17 Feldman S, Reinhard M, Willson CJ. Effect of sodium taurodeoxycholate on biological membranes; Release of phosphorus, phospholipid, and protein from everted rat small intestine. J Pharm Sci 1973; 62: 1961-4.

18 Cobden J, Rothwell J, Axon ATR, Passive permeability in experimental intestinal damage in rats. Clin Sci 1981; 60: 115-8.

19 Rhodes RS, Karnovsky MJ. Loss of macromolecular barrier function associated with surgical trauma to the intestine. Lab Invest 1971; 25: 220-9.

20 Moore JD, Zatsman ML, Overack DE. The effects of synthetic surfactants on intestinal permeability to glucose in vitro. Proc Soc Exp Biol (NY) 1971; 137: 1135-39.

21 Helenius A, Simons K. Solubilization of membranes by detergents. Biochim Biophys Acta 1975; 415: 29-79.

22 Weltzien HK. Cytolytic and membrane-perturbing properties of lysophosphatidylcholine. Biochim Biophys Acta 1979; 559: 259-87.

23 Ammon HV, Loeffler RE, Luedtke LA. Effects of lysophosphatidylcholine on jejunal water and solute transport in the rat in vivo. Lipids 1983; 18: 428-33.

24 Borgström B. Studies of the phospholipids of human bile and small intestinal content. Acta Chem Scand 1957; 11: 749.

25 Porter HP, Saunders DR. Isolation of the aqueous phase of human intestinal contents during the digestion of a fatty meal. Gastroenterology 1971; 60: 997-1007.

26 Bolin T, Heuman R, Sjödahl R, Tagesson C. Decreased lysophospholipase and increased phospholipase $A_{2}$ activity in ileal mucosa from patients with Crohn's disease. Digestion 1984; 29: 55-59.

27 Hirata F, Corcoran BA, Venkatasubramanian K, Schiffman E, Axelrod J. Chemoattractants stimulate 
degradation of methylated phospholipids and release of arachidonic acid in rabbit leukocytes. Proc Natl Acad Sci USA 1979; 76: 2640-43.

28 Reman FC, Demel RA, DeGier J, van Deenen LLM, Eibl H, Westphal O. Studies in the lysis of red cells and bimolecular lipid leaflets by synthetic lysolecithins, lecithins and structural analogs. Chem Phys Lipids 1969; 3: 221-33.

29 Joist JH, Dolezel G, Cucuianu MP, Nishizawa EE, Mustard JF. Inhibition and potentiation of platelet function by lysolecithin. Blood 1977; 49: 101-112.
30 Martin TW, Lagunoff D. Interactions of lysophospholipids and mast cells. Nature (London) 1979; 279: 250-2.

31 Andersson WB, Jaworski CJ. Modulation of adenylate cyclase activity of fibroblasts by free fatty acids and phospholipids. Arch Biochem Biophys 1977; 180: 374-83.

32 Shier WT, Baldwin JH, Nilsen-Hamilton M, Hamilton RT, Thanassi NM. Regulation of guanylate and adenylate cyclase activities by lyso lecithin. Proc Natl Acad Sci USA 1976; 73: 1586-90. 